\section{Records of Fatalities from Falling Meteorites}

With reference to Mr. M. A. R. Khan's letter in NATURE of October 12, p. 607, on the above subject, I would point out that Col. G. H. Saxton's letter ${ }^{1}$ regarding the Nedagolla meteorite of January 23, 1870 , states that of the people in the village, who were greatly alarmed, "some received violent shocks and a man near to whom it fell, was stunned". Apparently the man was not hit, but was stunned by the air pressure.

In the original account ${ }^{2}$ of the Mhow meteorite, also referred to by Mr. Khan, it is stated that the largest fragment weighed three pounds, and fragments were picked up four or five miles apart; "one broke a tree, and another wounded a man severely in the arm". However, the authority for the statement is not given and in default of substantiation, it is best, like "The Writer of the Review", to accept Prof. Heide's statement.

Mr. Khan should refer to my account ${ }^{3}$ of the Naoki meteoric shower of September 29, 1928, to which his ${ }^{4}$ is supplementary.

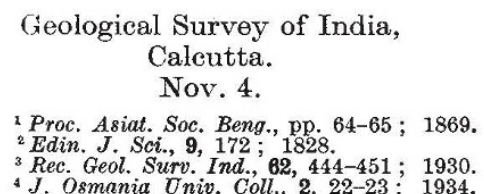

A. M. Heron.

\section{Absorption Spectra of Tautomeric Selenazoles}

THE ultra-violet absorption curve of 1-hydroxyl benzselenazole in methyl alcohol is almost identicawith that of 1-keto-2-methyl-1:2-dihydrobenzselenazole, and quite distinct from that of the $o$-methyl ether. In aqueous sodium hydroxide solution, the curve of the hydroxyselenazole is shifted to the left (deformation), and there is a decrease in maximum due to the production of the ion

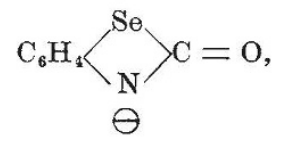

on which tautomeric change depends.

1-Thiolbenzselenazole also shows a striking similarity to thiazole analogues in the ultra-violet region, the curve in methyl alcohol being closely similar to that of 1-thio-2-methyl-1 : 2-dihydrobenzselenazole. The absorption curve for the thiolselenazole in aqueous sodium hydroxide belongs to the same family, but shows a slight shift towards the region of shorter wave-length, and an appreciable drop at the first maximum on account of the removal of mobile hydrogen.

Department of Chemistry,

R. F. HUNTER. Aligarh, India.

\title{
Points from Foregoing Letters
}

TAKing as variables the "preparedness for war", "defence coefficients", "fatigue and expense coefficients", and "dissatisfaction with treaties", Dr. L. F. Richardson expresses by means of differential equations the tendency towards war or peace. $\mathrm{He}$ deduces that the international system is unstable if the product of the two defence coefficients exceeds the product of the two fatigue coefficients and may drift either towards war or co-operation, according to the value of the different constants in the equations.

The effect of gamma-rays and of neutrons upon colloidal dispersions (gold and silver, arsenic and cadmium sulphides, vanadium pentoxide, ferric hydroxide) and upon chemical reactions (oxidation of potassium metabisulphite and decomposition of hydrogen peroxide) has been investigated by Prof. $F$. L. Hopwood and J. T. Phillips, with the view of obtaining a method for the detection of neutrons, not dependent on the formation of radioactive subtances, which are variable with time. They have detected an effect upon the chemical reactions and also changes in the stability of the colloidal dispersions.

Experiments carried out below ground at a depth equivalent to $60 \mathrm{~m}$. of water, by D. H. Follett and J. D. Crawshaw, show that cosmic rays which penetrate to this depth have, proportionately, the same ability to produce electron showers as those at the earth's surface, thus indicating that they consist of positive or negative electrons. These findings are not in agreement with those of previous investigators, who have reported rapid diminution of the ratio of the rate of shower production, or even complete absence of showers, at lesser depths.

The radioactivation of silver by neutrons at different temperatures and after traversing different thicknesses of paraffin (with a cadmium shield interposed at various distances) has been investigated by Drs. P. Preiswerk and H. von Halban, Jun. They find, in accordance with Fermi's theory, that for silver nuclei the chance of capture varies inversely as the relative velocity of nucleus and neutron, when account is taken of the velocity of thermal neutrons; this result does not hold for collisions of neutrons with the hydrogens of paraffin wax. The authors further find, unlike Moon and Tillman, that cooling the paraffin wax to $90^{\circ} \mathrm{K}$. increases by 10 per cent the radioactivity induced in iodine.

The catalytic dehydrogenation of alcohols, paraffins and olefines at a hot platinum or hot carbon surface has been studied by $\mathrm{O}$. Beeck by means of a molecular beam technique. $\mathrm{He}$ finds that a monomolecular layer of water is necessary in order to render the surface catalytically active, and that for all cases except methane the primary reaction is a splitting into free radicles (methane splits to free methylene and molecular hydrogen). At lower temperatures an excess of water inhibits the reaction. Water is, apparently, also necessary for the reverse (hydrogenation) reaction.

The presence of various hormones in the thyroid and pituitary glands, pancreas, ovary and corpus luteum of the blue whale has been ascertained by Dr. A. P. Jacobsen.

In connexion with Crawshay's recent suggestion that a phosphorescent syllid may have been responsible for the light "like the flame of a small candle" observed by Columbus after sunset on approaching the American shores, E. Berkeley gives further particulars of the swarming habits of Odontosyllis phosphorea at Departure Bay, B.C. 